\title{
Contemporary risk factors for ureteral stricture following renal transplantation
}

Anna J. Black; David Harriman; Christopher Nguan

Department of Urologic Sciences, University of British Columbia, Vancouver, BC, Canada

Cite as: Black AJ, Harriman D, Nguan C. Contemporary risk factors for ureteral stricture following renal transplantation. Can Urol Assoc J 2022 January 27; Epub ahead of print. http://dx.doi.org/10.5489/cuaj.7648

Published online January 27, 2022

Corresponding author: David Harriman, Department of Urologic Sciences, University of British Columbia, Vancouver, BC, Canada; david.harriman@ubcurology.com

$* * *$

\section{Abstract}

Introduction: Allograft ureteral strictures after renal transplantation impact graft function and increase patient morbidity. They can be challenging to treat and may require complex surgical repair. Therefore, the objective of this study was to identify contemporary risk factors for the development of post-renal transplant ureteral strictures.

Methods: A retrospective analysis was performed on all renal transplant patients at Vancouver General Hospital from 2008-2019. Demographics, clinical parameters, and outcomes were compared between patients who did and did not develop ureteral strictures. Putative risk factors for ureteral stricture were analyzed using logistic regression.

Results: A total of 1167 patients were included with a mean followup of $61.9 \pm 40.8$ months. Ureteral strictures occurred in 25 patients $(2.1 \%)$. Stricture patients had no demographic differences compared to non-stricture patients but had significantly higher rates of postoperative complications, longer hospital stays, and decreased renal function one-year post-transplant (all $\mathrm{p}<0.05$ ). On multivariable analysis, cold ischemia time $>435$ minutes (odds ratio $[\mathrm{OR}] 43.9$, confidence interval [CI] 1.6-1238.8, $\mathrm{p}=0.027$ ), acute rejection (OR 3.0, CI 1.1-7.4, p=0.027), and postoperative complications (OR 112.4, CI 2.4-5332.6, $\mathrm{p}=0.016$ ) were risk factors for stricture.

Conclusions: Renal transplant patients with ureteral stricture experience greater morbidity and reduced post-transplant renal function compared to non-stricture patients. Our findings support attempts to reduce cold ischemia time, acute rejection, and postoperative complications to mitigate this potential complication. Our study is limited by the low incidence of ureteral 
stricture resulting in a small sample of stricture patients. Future research in a larger, multicenter setting is warranted.

\section{Introduction}

Renal transplantation is the gold standard renal replacement therapy with established benefits in improving quantity and quality of life for end stage renal disease (ESRD) patients, and represents one of the most cost effective health care measures in medicine. ${ }^{1-3}$ However, approximately $0.5-$ $4.0 \%$ of patients develop a ureteral stricture after transplantation, which is associated with increased morbidity, can threaten graft function, and may require complex surgical repair. ${ }^{4}$

Streeter et al. suggested that post-transplant ureteral complications are caused by either surgical errors, including injury to the ureteral blood supply during harvest, or failed tissue healing, which is influenced by infection, ischemia, and inflammation. ${ }^{5,6}$ In fact, multiple studies have hypothesized that ischemia is the most responsible factor for ureteral stricture. ${ }^{7,8}$ This hypothesis is based on the observation that the number of allograft arteries, donor age, and delayed graft function have been associated with an increase in ureteral strictures. $1,5,7,9$ Inflammation resulting from acute rejection has also been implicated as a risk factor for ureteral stricture. ${ }^{10-12}$

Although post-renal transplant ureteral strictures have been studied, the majority of analyzed data stems from the 1970s to early 2000s. Over the last two decades, renal transplantation has evolved significantly. Advances in immunosuppression and machine perfusion have facilitated the use of expanded criteria donors, while new diagnostic techniques have led to earlier detection of and intervention for antibody-mediated rejection. ${ }^{13,14}$ Therefore, this study aims to re-examine risk factors for ureteral stricture in a contemporary patient cohort using a local database review. We hypothesize that factors associated with poor tissue healing and inflammation including poor donor quality, long ischemic time, delayed graft function, and acute rejection may be associated with ureteral stricture formation.

\section{Methods}

\section{Patients}

This study was conducted under an approved University of British Columbia Clinical Research Ethics Board certificate (H19-03830). A retrospective analysis was completed on all patients who received a renal transplant at Vancouver General Hospital between January 2008 and December 2019. Demographic, clinicopathological and outcome data were extracted from the Patient Records and Outcome Management Information System (PROMIS) maintained by the Provincial Renal Agency (PRA) and institutional electronic medical records.

Potential risk factors for ureteral stricture were identified through a literature review and recorded. These included recipient factors (age, smoking, comorbidities, pre-transplant estimated 
glomerular filtration rate (eGFR), cause of end-stage renal disease, type of and days on renal replacement therapy (RRT)), immunologic factors (HLA and ABO mismatch, percent panel reactive antibodies, immunosuppression induction and maintenance regimens), and donor factors (live, biologically related, expanded criteria donor (ECD), donation after cardiac death (DCD), and number of renal veins, arteries, and ureters). All post-operative complications were documented and graded by severity on a scale of 1 to 5 according to Common Terminology Criteria for Adverse Events (CTCAEv5) [15]. Immunosuppression regimens followed the BC Clinical Guidelines for Kidney Transplantation [16]. The Lich-Gregoir extravesical reimplant technique was used for all ureteral anastomoses, and 5-French 12-centimeter double J ureteric stents were placed in all patients that underwent transplantation after 2011, following the retirement of one of the surgeons whose preference was not to stent routinely. Drains were not routinely placed. Anastomotic time, cold ischemic time, duration of surgery, stent placement, blood loss, delayed graft function, length of hospital stay, and hospital readmission rates were all documented. Duration of follow-up as well as status at last follow-up was recorded.

Ureteral stricture was defined as any radiologically diagnosed narrowing of the ureter requiring intervention (stenting, nephrostomy tube insertion, balloon dilatation, or surgical repair) and excluded external compression of the ureter. Time to ureteral stricture, time to intervention, type of intervention, and intervention outcomes were recorded for all ureteral stricture patients.

\section{Statistical analysis}

Patients who received multiorgan or en-bloc transplants were excluded from the analysis. In addition to a descriptive analysis, demographic and clinical parameters were compared between patients who did or did not develop ureteral stricture using double-sided student T-test for continuous variables and chi-squared or Fisher's exact test for the binary and categorical variables. A multivariable analysis for risk factors for ureteral stricture included all statistically significant variables from the univariable analysis and all variables implicated as risk factors in previous studies. A binary logistic regression was used, and a $p$-value of $<0.05$ was considered significant.

\section{Results}

A total of 1167 patients receiving a renal transplant at Vancouver General Hospital between January 2008 and December 2019 were included in this study (Figure 1). Patient demographics are summarized in Table 1. Deceased donor renal transplants were more common than live donor transplants in both stricture and non-stricture groups (61.6\%; Supplemental Table 1). Of the deceased donors, $21.6 \%$ were DCD and $51.7 \%$ were from ECDs. Only $2.0 \%$ of live donors were ECDs, while $41.3 \%$ were related.

The vast majority of patients had ureteral stents placed intra-operatively (95.8\%), which were left in place for a mean of $46.6 \pm 11.4$ days. Nineteen patients $(1.7 \%)$ were identical HLA matches to their donors and thus received only methylprednisone as immunosuppression 
induction. Patients with HLA mismatch were induced with Basiliximab or anti-thymocyte globulin (ATG). Basiliximab with a rapid steroid taper was administered in $46.9 \%$ of patients. Patients were most commonly maintained on tacrolimus (99.2\%) and mycophenolate mofetil (MMF, 91.6\%). Patients who did not tolerate MMF received mycophenolate sodium (MYF, $5.8 \%$ ), azathioprine (AZA, $2.0 \%$ ) or sirolimus (SIR, $0.3 \%$ ).

Twenty-five of 1167 patients (2.1\%) developed a ureteral stricture at a mean of 107 days posttransplant (range of 3 to 642 days, Supplemental Table 2). Diagnoses were made using antegrade pyelograms through nephrostomy tubes placed due to hydronephrosis and renal dysfunction. Ureteral strictures were managed with balloon dilatation (8 patients), surgical repair ( 8 patients), balloon dilatation followed by surgical repair (3 patients), or stenting ( 6 patients). Only $12 \%$ of patients required chronic stenting, while $84 \%$ were cured. All patients who underwent balloon dilatation or surgery were cured with no recurrence of stricture. Demographics, donor characteristics, and pre-stricture treatment details did not differ significantly between patients with and without a ureteral stricture on a univariable analysis.

Table 2 highlights functional outcomes and post-operative complications between groups. Stricture patients had more post-operative complications including fascial wound dehiscence, hematoma, abscess, urinary tract infection, and graft rejection (all $p<0.05$ ), and an increased length of stay in hospital ( $13.5 \pm 9.6$ vs $8.2 \pm 6.5$ days, $p=0.01$ ). In 6 stricture patients, discharge was delayed due to complications requiring repeat surgeries (hemorrhage, wound dehiscence, intra-abdominal abscess), while 3 required admission to the ICU (anaphylaxis, cardiac arrest, hypotension), and 1 had a stricture repair prior to discharge. Allograft survival (Figure 2) and overall survival (Figure 3) were not different between stricture and non-stricture patients.

Using a receiver operating characteristic curve we identified a cold ischemia time of 435 minutes as the optimal cut-off for predicting ureteral stricture (sensitivity $76 \%$, specificity $59 \%$ ). In the multivariable analysis (Table 3), cold ischemic time $>435$ minutes (odds ratio (OR) 43.9, 95\% confidence interval (CI) 1.6-1238.8, $p=0.027$ ), acute rejection (OR 3.0, CI 1.1-7.4, $p=$ 0.027 ), and post-operative complications (OR 112.4, CI 2.4-5332.6, $p=0.016$ ) were significant risk factors for ureteral stricture. The number of stricture events did not justify analyzing each type of post-operative complication individually in the multivariable analysis, but, if analyzed in this way, deep infections (urinoma (OR 73.5, CI 3.4-1589, $p=0.006$ ), abscess (OR 20.5, CI 2.6$162.8, p=0.004$ ), and urinary tract infection (OR 3.7, CI 1.5-9.3, $p=0.004)$ ) were the only significant post-operative complications. When included in the multivariable analysis, allograft side (right versus left donor kidney) was not a significant risk factor for stricture $(\mathrm{p}=0.831)$. A separate multivariable analysis including only deceased donor transplants was run and demonstrated that $\mathrm{DCD}$, when compared to NDD, is not a risk factor for ureteral stricture (OR 0.63 , CI $0.16-2.5, p=0.51$ ).

\section{Discussion}

We observed an overall transplant ureteral stricture rate of $2.1 \%$ after a mean follow-up of 5 years. Cold ischemia time (CIT) $>435 \mathrm{~min}$, acute rejection, and post-operative complications 
were adverse risk factors, supporting the hypothesis that variables associated with ischemia, inflammation, and infection are associated with a higher risk of ureteral stricture.

Delayed graft function (DGF), an indirect indicator of ischemia, is the most commonly described risk factor for ureteral stricture. ${ }^{4,5,9,17}$ CIT is a direct measure of ischemia that typically correlates with DGF because DGF often develops due to the ischemic and re-perfusion damage following prolonged CIT. ${ }^{11}$ However, prior studies failed to show a direct relationship between CIT and ureteral stricture. ${ }^{1,4,17}$ This may be because they analyzed CIT as a continuous rather than binary variable. In our study, CIT, instead of DGF, was a risk factor for ureteral stricture, and was only significant when assessed as a binary variable. There are no studies examining the histopathological effects of ischemia time on the ureter.

In addition to pre-transplant ischemia time, poor post-transplant perfusion can result in ureteral ischemia. The presence of $>2$ renal arteries and advanced donor age have been implicated as risk factors for ureteral stricture. Carter et al. suggested that the presence of multiple allograft arteries is correlated with poor inferior pole perfusion leading to relative ureteral ischemia, while Karam et al. proposed that the quality of the vascular supply to the ureters declines with age. ${ }^{7,18}$ However, these were not significant risk factors for ureteral stricture in our study. This may be due to the relatively low number of patients with older donor age and $>2$ arteries in our series ( $n=102$ aged $>65$ and $n=35$ with $>2$ renal arteries).

Acute graft rejection was a risk factor for ureteral stricture in our study, a trend that has been seen in multiple previous studies. ${ }^{10,12,19}$ Histopathological examination of allograft ureters following episodes of acute rejection has shown that rejection involves the ureter in addition to the allograft kidney. ${ }^{11,12}$ Therefore, acute rejection causes ureteral inflammation, edema, and vascular damage, followed by ureteral fibrosis which can ultimately lead to ureteral stricture. ${ }^{20}$

Infection affects wound healing by similar mechanisms as inflammation and is also thought to increase risk of ureteral stricture. ${ }^{5}$ Urinary tract infection, urinoma, and abscess can all potentially involve the ureter. In our series, post-operative complications were a significant risk factor for ureteral stricture, and this effect was driven especially by infectious complications. This suggests that further research examining methods to prevent complications like urinary tract infections is warranted, especially given that urinary tract infections are so common following renal transplantation ( $28.4 \%$ of patients).

Ureteral stricture was associated with significantly worse renal function at 1-year posttransplant in our univariable analysis. Although previous studies have demonstrated a significantly higher rate of graft loss in stricture patients, this was not the case in our study. Similar rates of graft loss despite worse renal function suggest that timely diagnosis and treatment of ureteral stricture in addition to advances in post-renal transplant patient care have improved allograft survival. ${ }^{21,22}$

As mentioned, our study is limited by the low incidence of ureteral stricture resulting in a small sample of stricture patients. This may have prevented the identification of other important risk factors for ureteral stricture. Additionally, the retrospective nature of our study introduces 
bias, as treatment is largely dependent upon recipient and donor factors. Both the small sample size and retrospective nature impede this study's ability to draw conclusions regarding which post-operative complications are risk factors for ureteral stricture, and how they are linked. Our follow-up period of 61 months limits our ability to accurately determine the true long term (10 year) incidence of ureteral stricture and long-term outcomes for these patients. However, the average time to stricture was 3 months, suggesting that the majority of ureteral strictures were captured in our analysis.

Mitigating risk factors for ureteral strictures, including cold ischemia time, acute rejection, and post-operative complications, may decrease the incidence of ureteral stricture and improve overall patient outcomes. While minimizing cold ischemia time and acute rejection continues to be an active field of research, simple measures may help reduce post-operative infectious complications. For example, recent studies suggest that increasing the dose of trimethoprim/sulfamethoxazole, which is routinely given for pneumocystis jirovecii pneumonia prophylaxis, results in fewer UTIs. ${ }^{23,24}$ However, this also increases the risk of side effects including renal dysfunction and hyperkalemia and has not yet been shown to improve overall patient outcomes. ${ }^{24}$ Decreasing the duration of ureteral stenting and removing the stents via an attached string rather than cystoscopy may also mitigate the incidence of UTIs. ${ }^{23-25}$ However, further research is required to elucidate the impact such measures have on the rate of stricture.

\section{Conclusions}

Renal transplant patients with ureteral stricture experience greater morbidity and reduced posttransplant renal function than non-stricture patients. Our analysis demonstrates that prolonged CIT, acute rejection, and post-operative complications are associated with a higher risk for ureteral stricture. This supports the theory that ischemia, inflammation, and infection may result in higher rates of ureteral strictures. Reducing cold ischemia time, acute rejection, and postoperative complications may help mitigate this potential complication. Future research in a larger, multicenter setting is warranted. 


\section{References}

1. Duty BD, Barry JM. Diagnosis and management of ureteral complications following renal transplantation. Asian J Urol 2015; 2:202-7.

2. Wolfe RA, Ashby VB, Milford EL, et al. Comparison of mortality in all patients on dialysis, patients on dialysis awaiting transplantation, and recipients of a first cadaveric transplant. $N$ Engl J Med 1999; 341:1725-30.

3. Wang JH, Skeans MA, Israni AK. Current Status of Kidney Transplant Outcomes: Dying to Survive. Adv Chronic Kidney Diss 2016; 23:281-6.

4. Giessing M. Transplant Ureter Stricture Following Renal Transplantation: Surgical Options. Transplant Proc 2011; 43:383-6.

5. Streeter EH, Little DM, Cranston DW, et al. The urological complications of renal transplantation: a series of 1535 patients. BJU Int 2002; 627-34.

6. Pereira H, Buchler M, Brichart N, et al. Sténoses urétérales après transplantation rénale: facteurs de risque et impact sur la survie. Prog Urol 2011; 21:389-96.

7. Karam G, Hetet JF, Maillet F, et al. Late Ureteral Stenosis Following Renal Transplantation: Risk Factors and Impact on Patient and Graft Survival. Am J Transplant 2006; 6:352-6.

8. Kumar S, Ameli-Renani S, Hakim A, et al. Ureteral obstruction following renal transplantation: causes, diagnosis and management. Br J Radiol 2014; 87:1-6.

9. Lempinen M, Stenman J, Kyllönen L, et al. Surgical complications following 1670 consecutive adult renal transplantations: a single center study. Scand J Surg 2014; 104:254-9.

10. Faenza A, Nardo B, Catena F, et al. Ureteral stenosis after kidney transplantation. Transpl Int 1999; 12:334-40.

11. Haber MH, Putong PB. Ureteral Vascular Rejection in Human Renal Transplants. JAMA $1965 ; 192: 157-9$.

12. Starzl TE, Groth CG, Putnam CW, et al. Urological Complications in 216 Human Recipients of Renal Transplants. Ann Surg 1970; 172:1-22.

13. Abramowicz D, Oberbauer R, Heemann U, et al. Recent advances in kidney transplantation: a viewpoint from the Descartes advisory board. Nephrol Dial Transplant 2018; 33:1699-707.

14. Lim MA, Kohli J, Bloom RD. Immunosuppression for kidney transplantation: Where are we now and where are we going? Transplant Rev 2017; 31:10-7.

15. National Cancer Institute. Common Terminology Criteria for Adverse Events (CTCAE). 2018 Feb 23:1-147. Available from: https://ctep.cancer.gov/protocoldevelopment/electronic_applications/docs/ctcae_v5_quick_ reference_8.5x11.pdf

16. PHSABC. Clinical Guidelines for Kidney Transplantation. 2018:1-66.

17. Perico N, Cattaneo D, Sayegh MH, Remuzzi G. Delayed graft function in kidney transplantation. Lancet 2004; 364:1814-27.

18. Carter JT, Freise CE, McTaggart RA, et al. Laparoscopic Procurement of Kidneys with Multiple Renal Arteries is Associated with Increased Ureteral Complications in the Recipient. Am J Transplant 2005; 5:1312-8. 
19. Rigg KM, Proud G, Taylor RMR. Urological complications following renal transplantation. Transplant Int 1994; 7:120-6.

20. Dreikorn K. Problems of the Distal Ureter in Renal Transplantation. Urol Int 1992; 49:7689.

21. Englesbe MJ, Dubay DA, Gillespie BW, et al. Risk Factors for Urinary Complications After Renal Transplantation. Am J Transplant 2007; 7:1536-41.

22. Arpali E, Al-Qaoud T, Martinez E, et al. Impact of ureteral stricture and treatment choice on long-term graft survival in kidney transplantation. Am J Transplant 2018; 18:1977-85.

23. Ness D, Olsburgh J. UTI in kidney transplant. World J Urol 2020; 38:81-8.

24. Goldman J, Julian K. Urinary tract infections in solid organ transplant recipients: Guidelines from the American Society of Transplantation Infectious Diseases Community of Practice. Clin Transplant. 2019; 33:e13507.

25. Patel P, Rebollo-Mesa I, Ryan E, et al. Prophylactic ureteric stents in renal transplant recipients: a multicenter randomized controlled trial of early versus late removal. Am J Transplant 2017; 17:2129-38. 


\section{Figures and Tables}

Fig. 1. Allocation of patients into stricture vs no-stricture, live (LD) vs. cadaver (CAD) kidney, donation after circulatory death (DCD) vs. neurological determination of death (NDD), and standard vs. expanded criteria donor (ECD) groups.

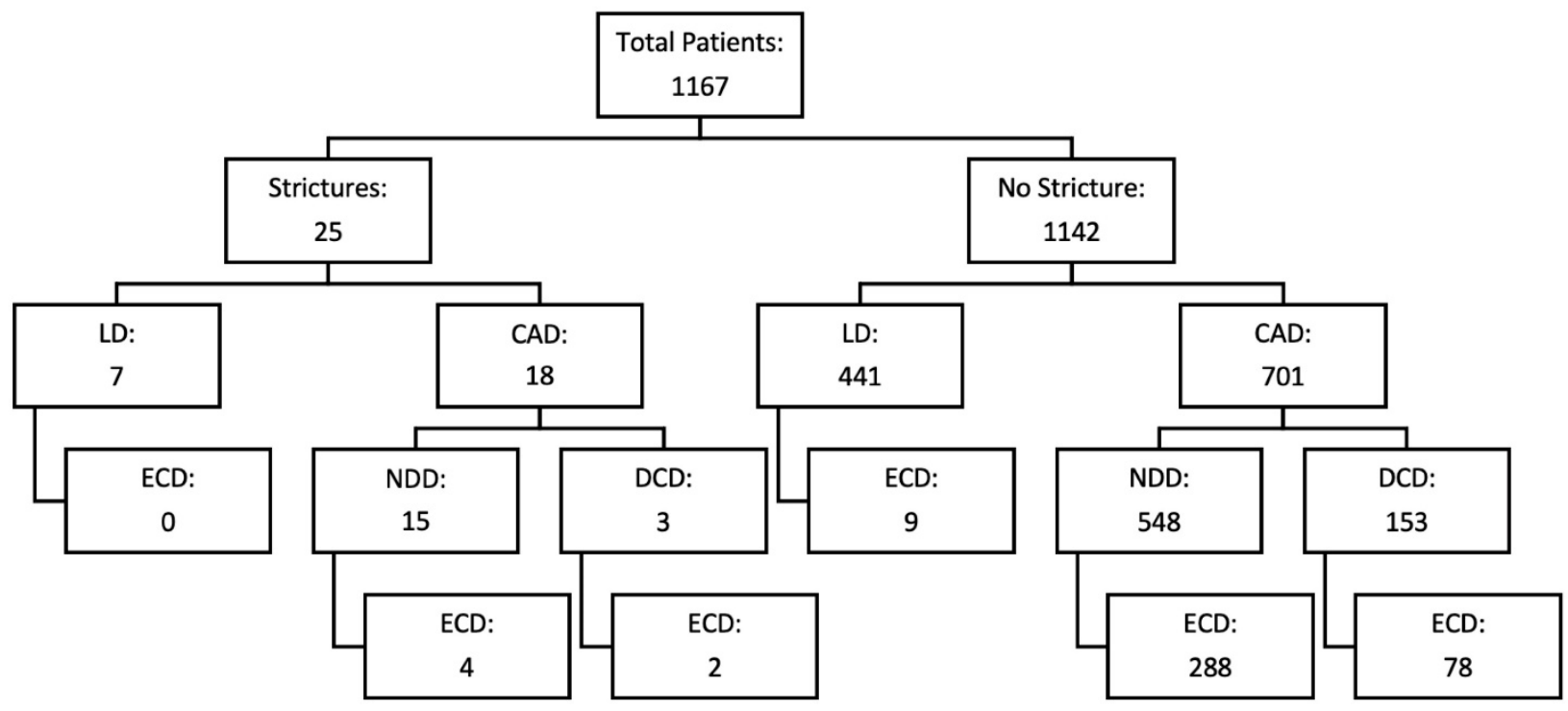


Fig. 2. Death-censored allograft survival after renal transplantation for patients who did (green) and did not (blue) develop a ureteral stricture. Allograft survival is defined as patients not requiring dialysis or repeat transplantation. Numbers below the $\mathrm{x}$-axis represent the number of patients at risk in each group (Mantel-Cox $\mathrm{p}=0.683$ ).

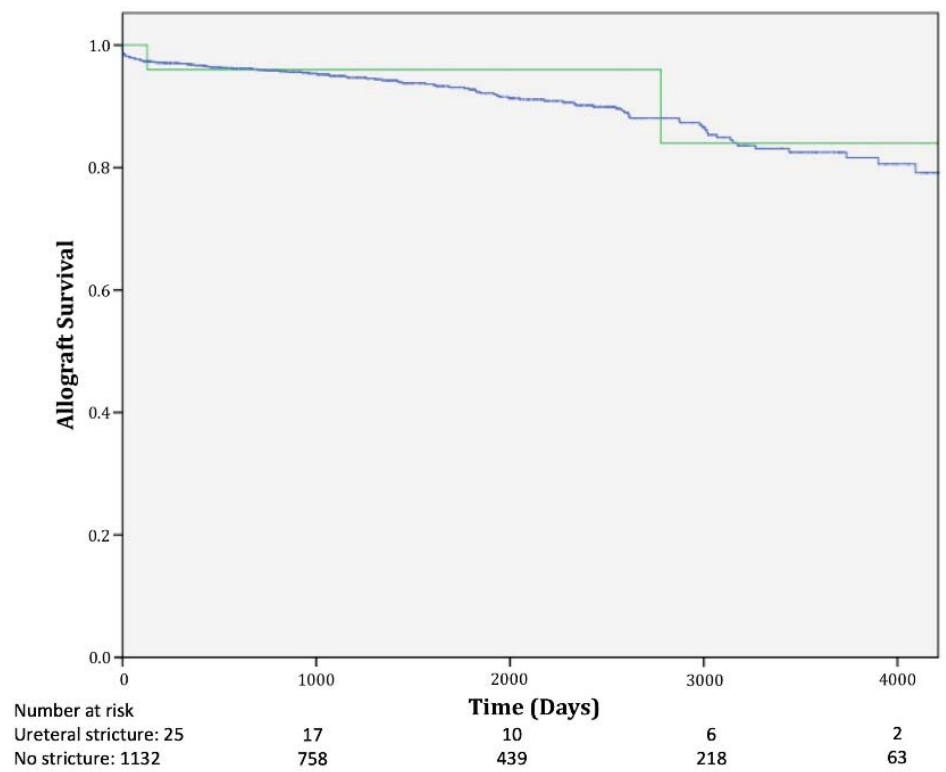

Fig. 3. Overall survival after renal transplantation for patients who did (green) and did not (blue) develop a ureteral stricture. Numbers below the $\mathrm{x}$-axis represent the number of patients at risk in each group (Mantel-Cox $\mathrm{p}=0.693$ ).

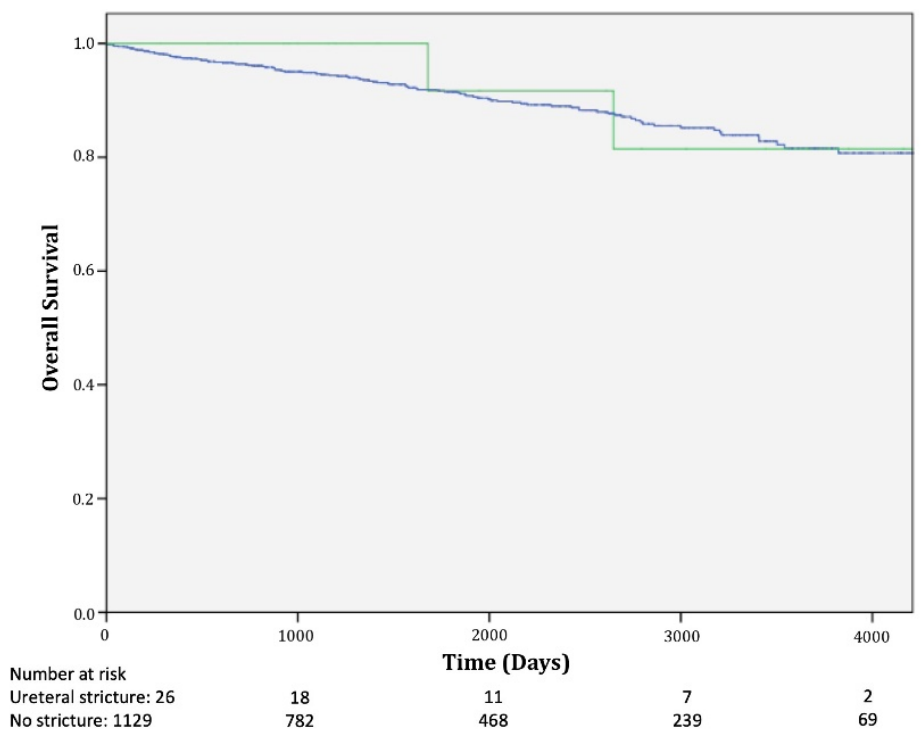




\begin{tabular}{|c|c|c|c|c|c|}
\hline \multicolumn{2}{|c|}{ Table 1. Recipient demographics, preo } & $\begin{array}{l}\text { No Stricture } \\
(\mathrm{n}=1142)\end{array}$ & $\begin{array}{l}\text { Stricture } \\
(\mathrm{n}=25)\end{array}$ & $\begin{array}{l}\text { Total } \\
(n=1167)\end{array}$ & $\mathbf{p}$ \\
\hline \multicolumn{2}{|c|}{ Followup (months; mean \pm SD) } & $60.8 \pm 40.2$ & $66.7 \pm 42.4$ & $61.2 \pm 40.3$ & 0.503 \\
\hline \multicolumn{2}{|l|}{ Age (years; mean $\pm \mathrm{SD}$ ) } & $52.4 \pm 13.7$ & $56.0 \pm 10.0$ & $52.5 \pm 13.6$ & 0.087 \\
\hline \multicolumn{2}{|l|}{$\begin{array}{l}\text { Body mass index } \\
\left(\mathrm{kg} / \mathrm{m}^{2} ; \text { mean } \pm \mathrm{SD}\right)\end{array}$} & $26.8 \pm 5.9$ & $27.5 \pm 4.4$ & $26.8 \pm 5.9$ & 0.591 \\
\hline \multicolumn{2}{|l|}{ Hypertension (n, \%) } & $1079(95.3 \%)$ & $25(100 \%)$ & $1104(95.4 \%)$ & 0.625 \\
\hline \multirow{3}{*}{$\begin{array}{l}\text { Smoker } \\
(n, \%)\end{array}$} & Current & $102(9.0 \%)$ & $2(8.0 \%)$ & $104(9.0 \%)$ & \multirow[t]{3}{*}{0.139} \\
\hline & Remote & $339(29.9 \%)$ & $12(48.0 \%)$ & $351(30.3 \%)$ & \\
\hline & Never & $691(61.0 \%)$ & $11(44.0 \%)$ & $702(60.7 \%)$ & \\
\hline \multirow{4}{*}{$\begin{array}{l}\mathrm{ABO} \\
(\mathrm{n}, \%)\end{array}$} & $\mathrm{O}$ & $476(41.9 \%)$ & $9(36.0 \%)$ & $485(41.8 \%)$ & \multirow[t]{4}{*}{0.953} \\
\hline & $\mathrm{A}$ & $419(36.9 \%)$ & $10(40.0 \%)$ & $429(37.0 \%)$ & \\
\hline & $\mathrm{B}$ & $178(15.7 \%)$ & $5(20.0 \%)$ & $183(15.8 \%)$ & \\
\hline & $\mathrm{AB}$ & $61(5.4 \%)$ & $1(4.0 \%)$ & $62(5.3 \%)$ & \\
\hline \multirow{4}{*}{$\begin{array}{l}\text { Renal replacement } \\
\text { therapy }(n, \%)\end{array}$} & Hemodialysis & $567(50.0 \%)$ & $8(32.0 \%)$ & $575(50.0 \%)$ & \multirow[t]{4}{*}{0.166} \\
\hline & $\begin{array}{l}\text { Peritoneal } \\
\text { Dialysis }\end{array}$ & $378(33.3 \%)$ & $13(52.0 \%)$ & $391(33.7 \%)$ & \\
\hline & Pre-dialysis & $166(14.6 \%)$ & $4(16.0 \%)$ & $170(14.7 \%)$ & \\
\hline & Unknown & $24(2.1 \%)$ & - & $24(2.1 \%)$ & \\
\hline \multirow{12}{*}{$\begin{array}{l}\text { Etiology of end-stage } \\
\text { renal disease } \\
(\mathrm{n}, \%)\end{array}$} & Solitary Kidney & $14(1.2 \%)$ & - & $14(1.2 \%)$ & \multirow[t]{12}{*}{0.443} \\
\hline & Reflux & $20(1.8 \%)$ & - & $20(1.7 \%)$ & \\
\hline & Obstruction & $26(2.3 \%)$ & - & $26(2.2 \%)$ & \\
\hline & Diabetes & $343(30.4 \%)$ & $5(20.0 \%)$ & $348(30.2 \%)$ & \\
\hline & Hypertension & $12(1.1 \%)$ & $1(4.0 \%)$ & $13(1.1 \%)$ & \\
\hline & Drug induced & $11(1.0 \%)$ & $1(4.0 \%)$ & $12(1.0 \%)$ & \\
\hline & $\begin{array}{l}\text { Glomerulo- } \\
\text { nephritis }\end{array}$ & $368(32.6 \%)$ & $10(40.0 \%)$ & $378(32.8 \%)$ & \\
\hline & Congenital & $32(2.8 \%)$ & $1(4.0 \%)$ & $33(2.9 \%)$ & \\
\hline & $\begin{array}{l}\text { Cystic kidney } \\
\text { disease }\end{array}$ & $114(10.1 \%)$ & $2(8.0 \%)$ & $116(10.1 \%)$ & \\
\hline & $\begin{array}{l}\text { Renal vascular } \\
\text { disease }\end{array}$ & $87(7.7 \%)$ & $4(16.0 \%)$ & $91(7.9 \%)$ & \\
\hline & Other & $27(2.4 \%)$ & - & $27(2.3 \%)$ & \\
\hline & Unknown & $75(6.6 \%)$ & $1(4.0 \%)$ & $76(6.6 \%)$ & \\
\hline \multirow{4}{*}{$\begin{array}{l}\text { Transplant number } \\
(\mathrm{n}, \%)\end{array}$} & First & $1038(91.5 \%)$ & $24(96.0 \%)$ & $1062(91.6 \%)$ & \multirow[t]{4}{*}{1.000} \\
\hline & Second & $77(6.8 \%)$ & $1(4.0 \%)$ & $78(6.7 \%)$ & \\
\hline & Third & $17(1.5 \%)$ & - & $17(1.5 \%)$ & \\
\hline & Fourth & $2(0.2 \%)$ & - & $2(0.2 \%)$ & \\
\hline \multicolumn{2}{|c|}{ Days on dialysis (mean $\pm \mathrm{SD}$ ) } & $1131 \pm 1041$ & $1461 \pm 1014$ & $1139 \pm 1039$ & 0.117 \\
\hline \multicolumn{2}{|c|}{$\%$ panel reactive antibodies (mean $\pm \mathrm{SD}$ ) } & $20.5 \pm 32.7$ & $30.8 \pm 40.1$ & $20.8 \pm 31.2$ & 0.071 \\
\hline HLA-A mismatch & 0 & $151(15.0 \%)$ & $3(12.5 \%)$ & $154(15.0 \%)$ & 0.635 \\
\hline
\end{tabular}




\begin{tabular}{|c|c|c|c|c|c|}
\hline \multirow[t]{2}{*}{$(n, \%)$} & 1 & $523(52.0 \%)$ & $15(62.5 \%)$ & $538(52.3 \%)$ & \\
\hline & 2 & $331(32.9 \%)$ & $6(25.0 \%)$ & $337(32.8 \%)$ & \\
\hline \multirow{3}{*}{$\begin{array}{l}\text { HLA-B mismatch } \\
(\mathrm{n}, \%)\end{array}$} & 0 & $77(7.7 \%)$ & - & $77(7.5 \%)$ & \multirow[t]{3}{*}{0.088} \\
\hline & 1 & $371(36.9 \%)$ & $14(58.3 \%)$ & $385(37.4 \%)$ & \\
\hline & 2 & $557(55.4 \%)$ & $10(41.7 \%)$ & $567(55.1 \%)$ & \\
\hline \multirow{3}{*}{$\begin{array}{l}\text { HLA-DR mismatch } \\
(\mathrm{n}, \%)\end{array}$} & 0 & $114(11.3 \%)$ & $4(16.7 \%)$ & $118(11.5 \%)$ & \multirow[t]{3}{*}{0.422} \\
\hline & 1 & $493(49.1 \%)$ & $13(54.2 \%)$ & $506(49.2 \%)$ & \\
\hline & 2 & $398(39.6 \%)$ & $7(29.2 \%)$ & $405(39.4 \%)$ & \\
\hline \multirow{3}{*}{$\begin{array}{l}\text { Immunosuppressive } \\
\text { induction }^{1}(\mathrm{n}, \%)\end{array}$} & None & $18(1.6 \%)$ & $1(4.0 \%)$ & $19(1.7 \%)$ & 0.454 \\
\hline & Basiliximab & $807(72.4 \%)$ & $18(72.0 \%)$ & $825(72.4 \%)$ & \\
\hline & ATG & $289(25.9 \%)$ & $6(24.0 \%)$ & $295(25.9 \%)$ & \\
\hline \multicolumn{2}{|c|}{ Anastomosis time (minutes; mean \pm SD) } & $34.8 \pm 10.7$ & $32.6 \pm 9.9$ & $34.7 \pm 10.6$ & 0.362 \\
\hline \multicolumn{2}{|c|}{ Surgery duration (minutes; mean $\pm \mathrm{SD}$ ) } & $227 \pm 64.6$ & $242 \pm 62.8$ & $227 \pm 64.5$ & 0.371 \\
\hline \multicolumn{2}{|c|}{ Estimated blood loss $(\mathrm{ml} ;$ mean $\pm \mathrm{SD})$} & $181 \pm 190$ & $174 \pm 133$ & $180 \pm 189$ & 0.866 \\
\hline \multicolumn{2}{|l|}{ Stent placement $(\mathrm{n}, \%)$} & $1086(95.8 \%)$ & $23(92.0 \%)$ & $1109(95.7 \%)$ & 0.294 \\
\hline \multicolumn{2}{|c|}{ Days stent in place (days; mean $\pm \mathrm{SD}$ ) } & $46.7 \pm 10.9$ & $44.5 \pm 25.9$ & $46.6 \pm 11.4$ & 0.680 \\
\hline
\end{tabular}

${ }^{1}$ All patients also received methylprednisone as part of their immunosuppression induction.

ATG: anti-thymoglobulin; Pred: prednisone; RST: rapid steroid taper; SD: standard deviation.

Table 2. Initial patient transplant outcomes

\begin{tabular}{|c|c|c|c|c|c|}
\hline & & $\begin{array}{l}\text { No stricture } \\
(\mathrm{n}=1142)\end{array}$ & $\begin{array}{l}\text { Stricture } \\
(n=25)\end{array}$ & $\begin{array}{l}\text { Total } \\
(n=1167)\end{array}$ & $\mathbf{p}$ \\
\hline Followup (months; m & ean \pm SD) & $60.8 \pm 40.2$ & $66.7 \pm 42.4$ & $61.2 \pm 40.3$ & 0.474 \\
\hline $\begin{array}{l}\text { Recipient eGFR } 1-\mathrm{m} \\
\left(\mathrm{ml} / \mathrm{min} / 1.73 \mathrm{~m}^{2} ; \mathrm{me}\right.\end{array}$ & $\begin{array}{l}\text { nth post-transplant } \\
\mathrm{n} \pm \mathrm{SD})\end{array}$ & $49.8 \pm 19.8$ & $38.8 \pm 21.3$ & $49.5 \pm 20.0$ & 0.007 \\
\hline $\begin{array}{l}\text { Recipient eGFR 1-ye } \\
\left(\mathrm{ml} / \mathrm{min} / 1.73 \mathrm{~m}^{2} ; \mathrm{me}\right.\end{array}$ & $\begin{array}{l}\text { or post-transplant } \\
( \pm \text { SD) }\end{array}$ & $57.4 \pm 19.8$ & $46.2 \pm 17.4$ & $57.1 \pm 19.8$ & 0.005 \\
\hline $\begin{array}{l}\text { Length of stay in hos } \\
\text { (days; mean } \pm \text { SD) }\end{array}$ & ital & $8.2 \pm 6.5$ & $13.5 \pm 9.6$ & $8.3 \pm 6.7$ & $<0.001$ \\
\hline Readmission within 3 & 0 days $(n, \%)$ & $95(8.4 \%)$ & $4(16.0 \%)$ & $99(8.5 \%)$ & 0.158 \\
\hline Delayed graft functio & $a^{1}(n, \%)$ & $235(20.9 \%)$ & $9(36.0 \%)$ & $244(21.2 \%)$ & 0.082 \\
\hline Urinoma $^{2}(\mathrm{n}, \%)$ & & $3(0.3 \%)$ & $1(4.0 \%)$ & $4(0.3 \%)$ & 0.084 \\
\hline Hematoma & Total $(n, \%)$ & $179(15.8 \%)$ & $8(32.0 \%)$ & $187(16.0 \%)$ & 0.048 \\
\hline & Grade $1^{3}$ & $71(6.3 \%)$ & $2(8.0 \%)$ & $73(6.3 \%)$ & \\
\hline & Grade 2 & $65(5.7 \%)$ & $2(8.0 \%)$ & $67(5.8 \%)$ & \\
\hline & Grade 3 & $34(3.0 \%)$ & $3(12.0 \%)$ & $37(3.2 \%)$ & \\
\hline & Grade 4 & $8(0.7 \%)$ & $1(4.0 \%)$ & $9(0.8 \%)$ & \\
\hline & Grade 5 & $1(0.1 \%)$ & - & $1(0.1 \%)$ & \\
\hline Lymphocele/seroma & Total $(n, \%)$ & $34(3.0 \%)$ & $2(8.0 \%)$ & $36(3.1 \%)$ & 0.180 \\
\hline
\end{tabular}




\begin{tabular}{|c|c|c|c|c|c|}
\hline & Grade 1 & $12(1.1 \%)$ & $1(4.0 \%)$ & $13(1.1 \%)$ & \\
\hline & Grade 2 & $4(0.4 \%)$ & - & $4(0.3 \%)$ & \\
\hline & Grade 3 & $18(1.6 \%)$ & $1(4.0 \%)$ & $19(1.6 \%)$ & \\
\hline \multirow{5}{*}{$\begin{array}{l}\text { Fascial wound } \\
\text { dehiscence }\end{array}$} & Total $(\mathrm{n}, \%)$ & $25(2.2 \%)$ & $3(12.0 \%)$ & $28(2.4 \%)$ & 0.020 \\
\hline & Grade 1 & $10(0.9 \%)$ & - & $10(0.8 \%)$ & \\
\hline & Grade 2 & $6(0.5 \%)$ & $1(4.0 \%)$ & $7(0.6 \%)$ & \\
\hline & Grade 3 & $8(0.7 \%)$ & $2(8.0 \%)$ & $10(0.9 \%)$ & \\
\hline & Grade 4 & $1(0.1 \%)$ & - & $1(0.1 \%)$ & \\
\hline \multirow[t]{4}{*}{ Abscess } & Total (n, \%) & $11(1.0 \%)$ & $3(12.0 \%)$ & $14(1.2 \%)$ & 0.003 \\
\hline & Grade 2 & $3(0.3 \%)$ & - & $3(0.3 \%)$ & \\
\hline & Grade 3 & $7(0.6 \%)$ & $3(12.0 \%)$ & $10(0.9 \%)$ & \\
\hline & Grade 4 & $1(0.1 \%)$ & - & $1(0.1 \%)$ & \\
\hline \multirow[t]{4}{*}{ Wound infection } & Total $(\mathrm{n}, \%)$ & $28(2.5 \%)$ & $2(8.0 \%)$ & $30(2.6 \%)$ & 0.135 \\
\hline & Grade 1 & $2(0.2 \%)$ & - & $2(0.2 \%)$ & \\
\hline & Grade 2 & $25(2.2 \%)$ & $2(8.0 \%)$ & $27(2.3 \%)$ & \\
\hline & Grade 3 & $1(0.1 \%)$ & - & $1(0.1 \%)$ & \\
\hline \multicolumn{2}{|c|}{ Urinary tract infection $(\mathrm{n}, \%)$} & $315(27.8 \%)$ & $14(56.0 \%)$ & $329(28.4 \%)$ & 0.002 \\
\hline \multirow{4}{*}{$\begin{array}{l}\text { Renal artery } \\
\text { thrombosis }\end{array}$} & Total (n, \%) & $8(0.7 \%)$ & - & $8(0.7 \%)$ & 1.000 \\
\hline & Grade 1 & $3(0.3 \%)$ & - & $3(0.3 \%)$ & \\
\hline & Grade 2 & $1(0.1 \%)$ & - & $1(0.1 \%)$ & \\
\hline & Grade 3 & $4(0.4 \%)$ & - & $4(0.3 \%)$ & \\
\hline \multirow{4}{*}{$\begin{array}{l}\text { Renal vein } \\
\text { thrombosis }\end{array}$} & Total (n, \%) & $8(0.7 \%)$ & - & $8(0.7 \%)$ & 1.000 \\
\hline & Grade 1 & $1(0.1 \%)$ & - & $1(0.1 \%)$ & \\
\hline & Grade 3 & $6(0.5 \%)$ & - & $6(0.5 \%)$ & \\
\hline & Grade 4 & $1(0.1 \%)$ & - & $1(0.1 \%)$ & \\
\hline \multirow[t]{4}{*}{ Graft rejection } & Total & $154(13.6 \%)$ & $8(32.0 \%)$ & $162(14.0 \%)$ & 0.016 \\
\hline & Cell-mediated (n, \%) & $122(10.7 \%)$ & $4(16.7 \%)$ & $126(10.9 \%)$ & \\
\hline & Antibody-mediated & $11(1.0 \%)$ & $2(8.3 \%)$ & $13(1.1 \%)$ & \\
\hline & Both & $12(1.1 \%)$ & $1(4.2 \%)$ & $13(1.1 \%)$ & \\
\hline \multicolumn{2}{|l|}{ BK viremia } & Unknown & $3(12.0 \%)$ & Unknown & N/A \\
\hline \multicolumn{2}{|c|}{$\begin{array}{l}\text { Time to graft rejection } \\
(\text { days; mean } \pm \text { SD) }\end{array}$} & $172 \pm 425$ & $653 \pm 1159$ & $198 \pm 497$ & 0.280 \\
\hline \multicolumn{2}{|c|}{ Other complication $(\mathrm{n}, \%)^{4}$} & $425(37.5 \%)$ & $18(72.0 \%)$ & $443(38.2 \%)$ & 0.001 \\
\hline \multicolumn{2}{|c|}{ Graft failure (n, \%) } & $107(9.4 \%)$ & $2(8.0 \%)$ & $109(9.4 \%)$ & 1.000 \\
\hline
\end{tabular}

${ }^{1}$ Defined as dialysis required in first week after transplantation. ${ }^{2}$ All grade 3 complications.

${ }^{3}$ Complications were graded by Common Terminology Criteria for Adverse Events (CTCAEv5).

${ }^{4}$ Includes all complications resulting from the transplantation and immunosuppression (NSTEMI, C. difficile, urethral stricture, pneumocystis jirovecii pneumonia, etc.). SD: standard deviation. 


\begin{tabular}{|c|c|c|c|c|}
\hline & \multirow[b]{2}{*}{ Odds ratio } & \multicolumn{2}{|c|}{ 95\% confidence interval } & \multirow[b]{2}{*}{$\mathbf{p}$} \\
\hline & & Lower & Upper & \\
\hline $\begin{array}{l}\text { Smoker } \\
\text { (Never-smoker) }\end{array}$ & 1.64 & 0.706 & 3.81 & 0.249 \\
\hline $\begin{array}{l}\text { Age } \\
\text { (Continuous) }\end{array}$ & 1.025 & 0.991 & 1.06 & 0.159 \\
\hline $\begin{array}{l}\text { Live donor } \\
\text { (Deceased donor) }\end{array}$ & 14.5 & 0.486 & 436 & 0.123 \\
\hline $\begin{array}{l}\text { ATG induction } \\
\text { (Basiliximab induction) }\end{array}$ & .906 & 0.342 & 2.40 & 0.843 \\
\hline $\begin{array}{l}\text { Expanded criteria donor } \\
\text { (Standard criteria donor) }\end{array}$ & .383 & 0.136 & 1.08 & 0.068 \\
\hline $\begin{array}{l}\text { Cold ischemia time }>435 \mathrm{~min} \\
(\leq 435 \mathrm{~min})\end{array}$ & 43.9 & 1.55 & 1239 & 0.027 \\
\hline $\begin{array}{l}\text { Ureteral stent } \\
\text { (No stent) }\end{array}$ & .722 & 0.145 & 3.60 & 0.691 \\
\hline $\begin{array}{l}\text { Delayed graft function } \\
\text { (Immediate function) }\end{array}$ & 1.15 & 0.442 & 2.97 & 0.780 \\
\hline $\begin{array}{l}\text { Graft rejection } \\
\text { (No rejection) }\end{array}$ & 2.90 & 1.13 & 7.43 & 0.027 \\
\hline $\begin{array}{l}\text { Postoperative surgical } \\
\text { complication }^{1} \\
\text { (No complication) }\end{array}$ & 17.2 & 2.03 & 146 & 0.009 \\
\hline
\end{tabular}

${ }^{1}$ Includes urinoma, hematoma, lymphocele/seroma, urinary tract infection, wound dehiscence, wound infection, abscess, and renal vein or artery thrombosis. ATG: anti-thymoglobulin; DCD: donation after circulatory death; NDD: neurological determination of death. 